\title{
Genetic and physical interaction of Meis2, Pax3 and Pax7 during dorsal midbrain development
}

Zsuzsa Agoston 1,2,4, Naixin Li, ${ }^{3,5}$, Anja Haslinger ${ }^{2,6}$, Andrea Wizenmann ${ }^{3,7}$ and Dorothea Schulte ${ }^{1,2^{*}}$

\begin{abstract}
Background: During early stages of brain development, secreted molecules, components of intracellular signaling pathways and transcriptional regulators act in positive and negative feed-back or feed-forward loops at the midhindbrain boundary. These genetic interactions are of central importance for the specification and subsequent development of the adjacent mid- and hindbrain. Much less, however, is known about the regulatory relationship and functional interaction of molecules that are expressed in the tectal anlage after tectal fate specification has taken place and tectal development has commenced.

Results: Here, we provide experimental evidence for reciprocal regulation and subsequent cooperation of the paired-type transcription factors Pax3, Pax7 and the TALE-homeodomain protein Meis 2 in the tectal anlage. Using in ovo electroporation of the mesencephalic vesicle of chick embryos we show that (i) Pax3 and Pax7 mutually regulate each other's expression in the mesencephalic vesicle, (ii) Meis2 acts downstream of Pax3/7 and requires balanced expression levels of both proteins, and (iii) Meis2 physically interacts with Pax3 and Pax7. These results extend our previous observation that Meis2 cooperates with Otx2 in tectal development to include Pax3 and Pax7 as Meis 2 interacting proteins in the tectal anlage.

Conclusion: The results described here suggest a model in which interdependent regulatory loops involving Pax3 and Pax7 in the dorsal mesencephalic vesicle modulate Meis2 expression. Physical interaction with Meis2 may then confer tectal specificity to a wide range of otherwise broadly expressed transcriptional regulators, including Otx2, Pax3 and Pax7.
\end{abstract}

\section{Background}

Progressive regionalization events subdivide the early developing neural tube into a series of distinct units, which are marked by the expression of specific combinations of transcriptional regulators and signaling molecules. Expression of many of these proteins broadly overlaps at early embryonic stages, but progressively restricts later in embryogenesis due to a series of positive and negative regulatory events. This leads to the generation of molecularly defined territories, which subsequently differentiate into anatomically and functionally different brain structures. A well-studied example for such regionalization events is the development of the mesencephalic alar plate, the anlage of the optic tectum in non-mammalian vertebrates or of the superior

\footnotetext{
* Correspondence: dorothea.schulte@kgu.de

${ }^{1}$ Institute of Neurology (Edinger Institute), J. W. Goethe University Medical

School, Heinrich Hoffmannstr. 7, 50628 Frankfurt, Germany

Full list of author information is available at the end of the article
}

colliculus in mammals. The optic tectum develops from the caudal most part of the dorsal aspect of Otx2 expression domain. Otx2 expression is an essential prerequisite for the development of all anterior brain structures, which is evident in the lack of fore- and midbrain derived structures in $0 t \times 2$ mutant mice [1-3]. Tectal development is tightly linked to the activity of the midhindbrain boundary (MHB) organizer, a group of cells located at the junction between the mesencephalic and metencephalic vesicles. Cells of the MHB organizer secrete long-range and short-range signaling molecules, which are necessary and sufficient for the development of the adjacent mid- and hindbrain structures [4]. Transplantation of the MHB region into the diencephalon, mesencephalon or rhombencephalon elicits the ectopic expression of mid-/hindbrain markers and the formation of ectopic polarized mesencephalic and cerebellar structures surrounding the graft [5-8]. This activity can be mimicked by local application of Fgf8, a
C Biomed Central

() 2012 Agoston et al; licensee BioMed Central Ltd. This is an Open Access article distributed under the terms of the Creative Commons Attribution License (http://creativecommons.org/licenses/by/2.0), which permits unrestricted use, distribution, and reproduction in any medium, provided the original work is properly cited. 
secreted protein normally expressed within the MHB organizer territory $[9,10]$. Induction and maintenance of Fgf8 expression and MHB organizer activity depends on multileveled genetic interactions of transcription factors and signaling molecules, which include (among others) the secreted molecules Wnt1, Wnt3a and Wnt10b, the nuclear proteins $P a x 2 / 3 / 5 / 7 / 8$, En1, En2, and $L m x 1 b$, all of which act in positive feedback loops with Fgf8 [4]. Conversely, feedback antagonists of Fgf8 signaling such as Sef, Spry1, Spry 2 and $M k p 3$ confine the organizer activity to a narrow ring of cells at the mid-hindbrain junction [4]. Positive and negative autoregulation thus shapes and maintains the MHB organizer.

Two transcription factors reported to contribute to MHB organizer maintenance are the paired-box transcription factors Pax3 and Pax7 [11,12]. Both proteins share extensive homologies in protein sequence and expression patterns and are therefore believed to have arisen from a gene duplication event [13]. The importance of Pax3 in dorsal neural tube and neural crest patterning and differentiation is evident in the human syndromes associated with Pax3 mutations (Waardenburg syndromes type I and type III) as well as in mouse Splotch mutants. By contrast, Pax7 mutant mice do not display major defects in central nervous system development, which suggests a significant degree of functional overlap of the two Pax proteins $[14,15]$. In fact, knockin of Pax7 can rescue the central nervous system and neural crest defects associated with the Pax3/Splotch mutant phenotype [16]. In chick embryos, Pax3 and Pax7 are expressed from the ten somite stage onwards in nested domains within the dorsal neural tube. By the 25-26 somite stage, mesencephalic Pax3 expression extends more ventrally than that of $\operatorname{Pax} 7$, whereas only Pax7 expression reaches rostrally into the telencephalic vesicle [[11]; and Figure 1). Although expression of both genes is not specific for the mid-hindbrain territory, ectopic expression of either one induced expression of MHB organizer associated genes including Fgf8 and En2 and elicited development of ectopic tectal structures [11].

We have previously reported a pivotal role for Meis 2 in tectal development [17]. Meis2 belongs to the TALE (three amino acid loop extension) class of homeodomain containing proteins, which function as regulators of cell proliferation and differentiation of various tissues and organs during development. Meis family proteins form dimeric and trimeric complexes with other transcription factors, including the closely related Pbx family, members of the HOX clusters, several other homeodomain containing proteins and some basic helix-loop-helix (bHLH) proteins [18]. Mesencephalic Meis2 expression commences around the 19-20 somite stage and thus later than Pax3 and Pax7. Within the mesencephalic vesicle, Meis 2 is largely confined to the tectal anlagen with sharp expression boundaries to the diencephalon and the MHB territory [17]. Meis2 is both necessary and sufficient for tectal development: introduction of a

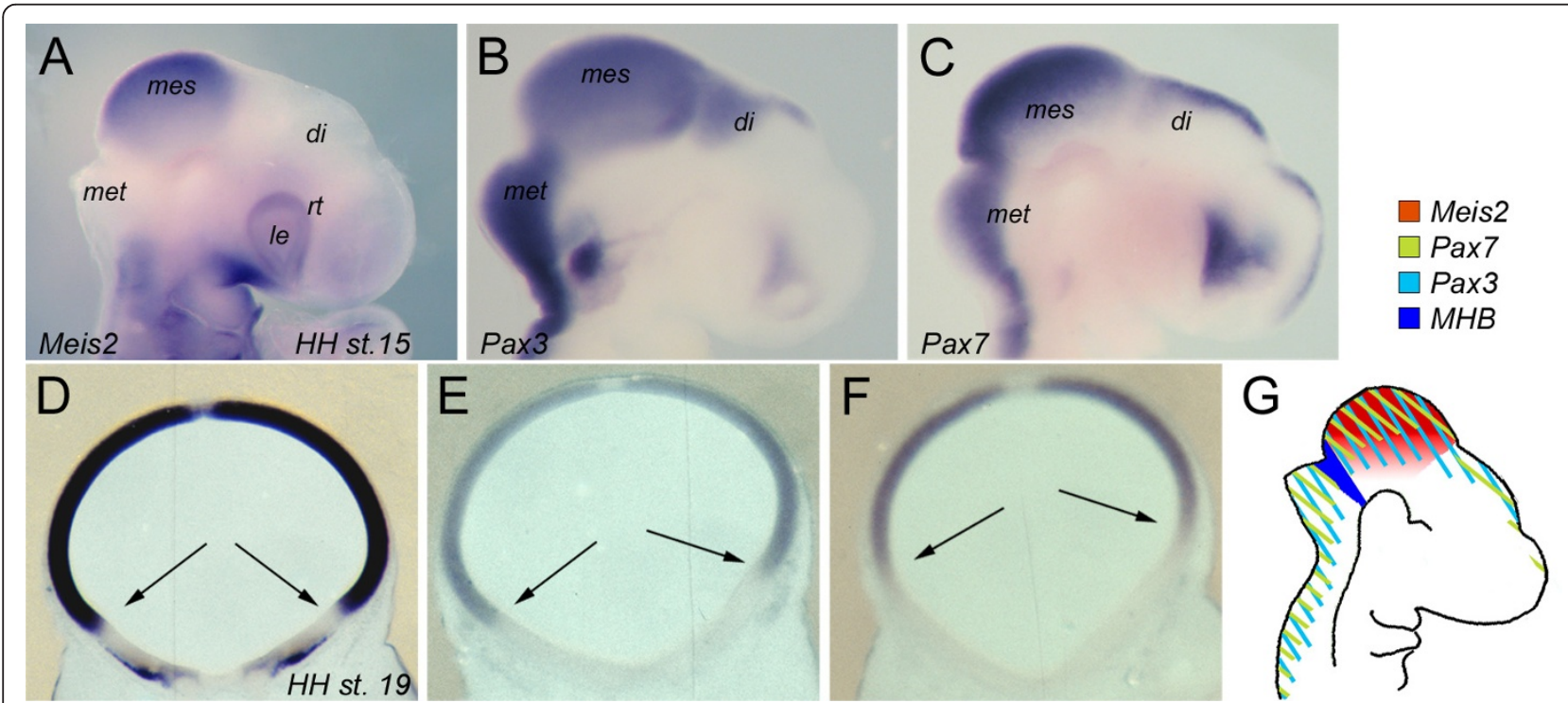

Figure 1 Meis2, Pax3 and Pax7 are expressed in nested domains in the HH15-19 chick midbrain. (A-G) Expression of Meis2 (A, D), Pax3 (B, E) and $\operatorname{Pax} 7(\mathbf{C}, \mathbf{F})$ as detected by in-situ hybridization on $\mathrm{HH} 15$ whole chick embryos $(\mathbf{A}-\mathbf{C})$ or neighboring vibratome cross sections through a HH19 mesencephalic vesicle (D-F). (G) Schematic summary of the expression patterns. di: diencephalic vesicle; le: lens; mes: mesencephalic vesicle; met: metencephalic vesicle; rt: retina. The arrows in (D-F) mark the ventral border of the respective expression domains. Panel (D) was taken from [17]. 
function blocking form of Meis2 into the mesencephalic vesicle abolishes normal tectal development, whereas a single, transient transfection of Meis2 in the diencephalic vesicle triggers the development of ectopic tectal structures. Meis2 lies downstream of Fgf8 in the hierarchy of tectum inducing genes, autoregulates its own expression and thereby stabilizes tectal fate $[17,19]$. The underlying mechanism, however, is only partially understood. One unique feature of Meis2 is its ability to induce a di- to mesencephalic fate change without any noticeable induction of Fgf8 expression. Instead, Meis2 directly interacts with Otx2 and competes with the Groucho co-repressor protein Tle4 for binding to Otx2, thereby releasing Otx2 from Tle4 mediated repression [17]. Whether Meis2 also associates with transcriptional regulators of tectal development other than Otx2 and what molecules regulate Meis 2 expression levels within the mesencephalic alar plate is not known yet. This is important, since Meis 2 autostimulates its own expression in the tectal anlage [17]. Some restraint needs therefore to be in place to prevent exuberant autoactivation of Meis2. So far, the nature of any inhibitory activity on Meis2 expression within the developing optic tectum remained elusive.

Here, we report a series of gain of function and biochemical experiments performed in chick embryos, which suggest that i) ectopic Pax7 expression induces $P a x 3$, ii) elevated expression levels of $P a x 3$ reduce expression of $\operatorname{Pax} 7$ and Meis2, but at different concentrations, which suggests Meis 2 expression requires a specific concentration threshold of $\operatorname{Pax} 3$ and $\operatorname{Pax} 7$, and iii) both paired domain proteins form heteromeric complexes with Meis2. These results show that interdependent regulatory loops involving $\operatorname{Pax} 3, \operatorname{Pax} 7$ and Meis2 exist in the tectal anlage and argue for a more general role of Meis 2 as co-factor of different transcriptional regulators of tectal development.

\section{Results}

Meis2, Pax3 and Pax7 are expressed in nested territories in the tectal anlage

A hallmark of early mid-/hindbrain fate specification is the mutual cross-regulation of proteins, which are expressed across the MHB organizer. Much less is known, however, about genetic interactions that may occur in the tectal anlage after initial fate specification has taken place. As a first step, we therefore compared the expression domains of Pax3, Pax7 and Meis2. Consistent with previous reports, we detected Pax3 and Pax7 transcripts at Hamburger Hamilton (HH) stage 15 (24-27 somites) in the alar plates of the spinal cord, and of the met-, mes- and diencephalic vesicles extending anteriorly to include prosomere 1 (Figure 1B, C, G) [11,20-24]. Pax7 was additionally expressed along the telencephalic midline. In contrast, Meis 2 expression was absent from the met-, diand telencephalon, but strongly expressed in the mesencephalic vesicle (Figure 1A, G) [17]. One day later, at HH19 (37-40 somites), Pax3, Pax7 and Meis2 transcripts were still abundant in the tectal anlage, as in-situ hybridization on adjacent vibratome sections showed (Figure 1D-F).

\section{Overexpression of $\operatorname{Pax} 7$ induces $\operatorname{Pax} 3$ but represses Meis2- and ephrin-B1}

To investigate a possible relationship between $\operatorname{Pax} 3$ and $P a x 7$ in the midbrain, we ectopically delivered an expression plasmid carrying $\operatorname{Pax} 7$ together with GFP (pMES-Pax7) by in ovo electroporation into the right lateral wall of the mesencephalic vesicle at $\mathrm{HH} 9-\mathrm{HH} 11$ (7-13 somite stage, Figure 2A). Due to the shot-gun nature of this gene delivery method, random patches of GFP expression, indicative of groups of cells forced to express the GFP and Pax7 transgenes, were seen across the right mesencephalic wall (Figure 2A, B"). Consistent with a previous report, we found that in these patches Pax3 expression was strongly induced as early as 16 hours following Pax7 misexpression (HH14, $n=15 / 19$ GFP expressing specimens exhibited strong ectopic Pax3 expression following electroporation of $2 \mu \mathrm{g} / \mu \mathrm{l}$ pMES-Pax7 (79\%); Figure 2B, B', C) [11]. Robust upregulation of Pax3 expression was still visible 24 hours and 36 hours after pMES-Pax7 transfection (HH18 and HH21 respectively, Figure 2D and data not shown). Ectopic Pax3 expression was also observed when Pax7 misexpression was specifically targeted to the ventral midbrain $(n=8 / 14$ GFP positive specimens exhibited ectopic Pax3 expression after targeted Pax7 expression into the ventral mesencephalic vesicle (57\%); Figure 2E). Scattered groups of cells expressing elevated levels of Pax3 transcripts were not only located within the territory of the endogenous Pax3 domains, but also reached ventrally towards the $N k x 6.1$ expression domain (Figure $\left.2 B^{\prime}, E^{\prime}\right)$. A comparison of Figure $2 B^{\prime}$ and Figure $2 B^{\prime \prime}$ revealed that apparently not all Pax7-GFP positive cells also express $\operatorname{Pax} 3$ mRNA, especially not in the ventral midbrain. This may be due to the short incubation time of the embryos after electroporation (HH9-11 to HH14) and may thus reflect incomplete upregulation of $\mathrm{Pax} 3$ by Pax7. In addition, gene delivery by in ovo electroporation causes targeted cells to take up varying amounts of DNA. Considering that ectopic induction of Pax3 may need a certain threshold of Pax7 protein (especially in the ventral neural tube, where Sonic hedgehog signaling promotes the induction of ventral cell fates $[25,26])$, it is possible that the ectopic Pax7 levels may not have reached the threshold necessary for Pax3 induction in all GFP-positive cells. In any case however, ectopic Pax3 expressing cells in the ventral mesencephalon were consistently positive for Pax7. 

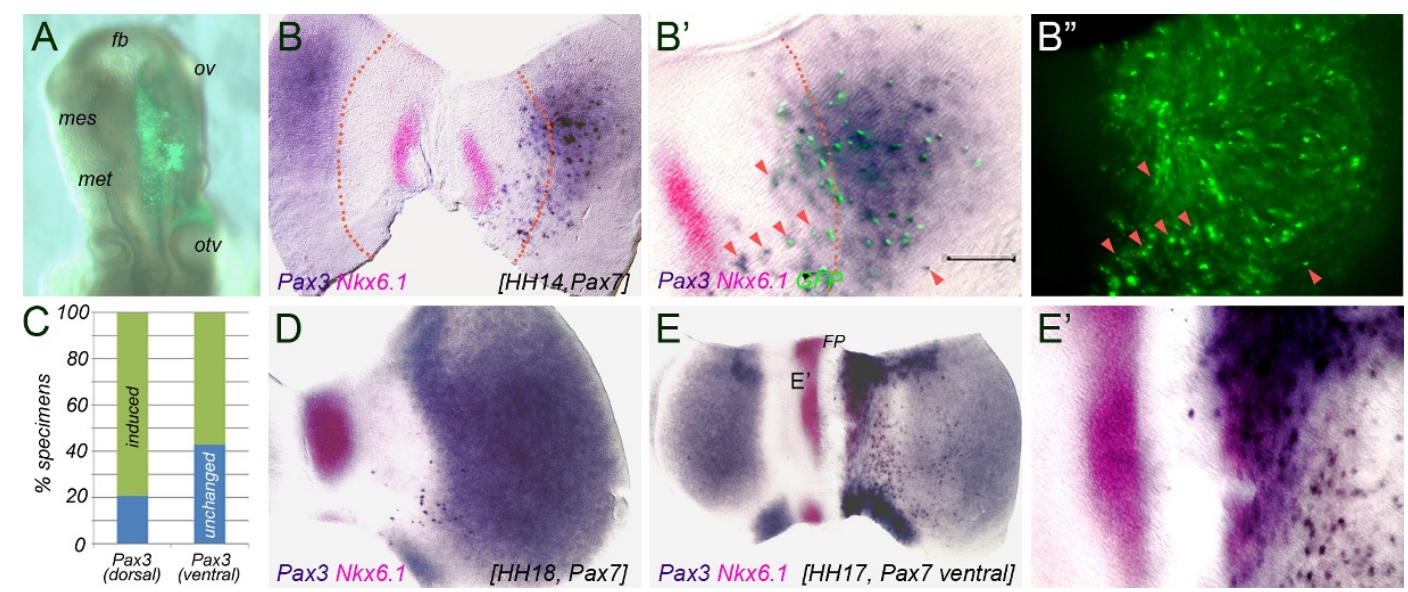

Figure 2 Pax7 induces Pax3 expression in the mesencephalic vesicle. (A) Representative example of pMES-Pax7 electroporation into the mesencephalic vesicle. GFP expression, indicative of transgene expression, is restricted to the right half of the neural tube 4-6 hours later. (B-B') Flat mount preparation of a HH14 chick neural tube, 16 hours after electroporation of $2 \mu \mathrm{g} / \mu \mathrm{l}$ pMES-Pax7 into the mesencephalic vesicle; Pax3 expression is in dark blue, Nkx6.1 expression in pink, GFP in green. The dotted lines mark the dorso-ventral boundary, the arrow heads indicate representative examples of ectopic Pax7 positive cells co-expressing Pax3. Ectopic patches of Pax3 expression are restricted to the right, electroporated half of the mesencephalic vesicle. (B') is a higher magnification of (B) with the GFP fluorescent image superimposed onto the preparation. $\left(\mathbf{B}^{\prime \prime}\right)$ shows the distribution of Pax7-GFP expressing cells in the specimen shown in $\left(\mathbf{B}^{\prime}\right)$. (C) Quantification of the results: percent specimens with induced (green bars) and unaltered (blue bars) Pax3 expression following targeted electroporation of pMES-Pax7. (D) Flat mount preparation of a HH18 chick neural tube, 24 hours after electroporation of $2 \mu \mathrm{g} / \mu \mathrm{l}$ pMES-Pax7. (E) Targeted misexpression of pMES-Pax7 into the ventral mesencephalic vesicle showing cells ectopically expressing Pax3 within the $N k \times 6.1$ domain. ( $\left.\mathbf{E}^{\prime}\right)$ is a higher magnification of $(\mathbf{E})$. fb: forebrain; fp: floor plate; mes: mesencephalic vesicle; met: metencephalic vesicle; ov: optic vesicle; otv: otic vesicle. Scale bar (B, B'): 100 m.

Two lines of evidence from our previous study suggested that Meis2 may not act upstream, but rather downstream of or in parallel to Pax3 and Pax7: (i) electroporation of a function blocking form of Meis2 into the mesencephalic vesicle had not affected $\operatorname{Pax} 3$ or $\operatorname{Pax} 7$ expression and (ii) ectopic delivery of Meis 2 into the diencephalon was not sufficient to induce expression of either Pax gene (Figure S4 of [17]). To explore a reciprocal relationship of the three proteins, we assessed Meis 2 expression following Pax7 misexpression. Contrary to our initial expectation, Meis2 specific transcripts were reduced in the midbrain vesicle after forced expression of $\operatorname{Pax} 7$ compared to embryos transfected with GFP alone, $(n=7 / 9$ embryos exhibited reduced Meis2 expression following electroporation of $2 \mu \mathrm{g} / \mu \mathrm{l}$ pMES-Pax7 (78\%); Figure 3A, B-B”, E). Likewise, expression of ephrinB1 (efnb1), a downstream target of Meis2 in the tectal anlage, was also diminished in Pax7 electroporated embryos $(n=5 / 7$ (71\%); Figure 3C, D-D', E) [17]. Thus, although all three genes are coexpressed within the tectal anlage, elevating Pax7 expression levels increased Pax3 but repressed Meis2 expression under identical experimental conditions.

\section{Midbrain Meis2- and Pax7 expression are repressed by Pax3 in a dose dependent manner}

To further explore this apparent contradiction, we ectopically expressed a HA-tagged form or Pax3 (pMIWIIIPax3-HA) in the mesencephalic vesicle. Meis2 expression was generally not affected following electroporation of concentrations between 0.1 to $1 \mu \mathrm{g} / \mu \mathrm{l}$ of the $\operatorname{Pax} 3$ expressing plasmid $(n=0 / 7$ embryos exhibited reduced Meis2 expression following electroporation of $0.1 \mu \mathrm{g} / \mu \mathrm{l}$ pMIWIII-Pax3-HA (0\%); $n=1 / 8$ following electroporation of $0.5 \mu \mathrm{g} / \mu \mathrm{l}(13 \%) ; n=0 / 8$ following electroporation of $1 \mu \mathrm{g} / \mu \mathrm{l}(0 \%)$; Figure $4 \mathrm{~A}, \mathrm{~B}, \mathrm{G})$. In contrast, transfection of $2 \mu \mathrm{g} / \mu \mathrm{l}$ of pMIWIII-Pax3-HA effectively repressed Meis2 transcripts ( $n=13 / 14$ (93\%); Figure 4C, G). Electroporation of $2 \mu \mathrm{g} / \mu \mathrm{l}$ of pMIWIII-Pax3-HA also repressed efnb1 expression ( $n=7 / 9$ (78\%), Figure 4D). Notably, Pax7 specific transcripts were lost in the dorsal midbrain already at a concentration of $1 \mu \mathrm{g} / \mu \mathrm{l}$ pMIWIIIPax3-HA (1 $\mu \mathrm{g} / \mu \mathrm{l}: n=6 / 7$ (86\%); $2 \mu \mathrm{g} / \mu \mathrm{l}: n=8 / 10$ (80\%); Figure 4E, F, G and data not shown). Thus, Pax7, like Meis2, is negatively regulated by $P a x 3$, but repression of Pax7 occurs already at half the concentration of the Pax3 expressing plasmid required to repress Meis 2 or its downstream gene efnb1. In summary, these results suggest that Pax7 induces $P a x 3$ and $P a x 3$ represses $P a x 7$ in the dorsal midbrain leading to tightly balanced expression levels of both proteins, which in turn are permissive for expression of Meis2 and its target gene efnb1.

Meis2-Pax3 and Meis2-Pax7 containing protein complexes exist in the tectal anlage

As we reported previously, Meis2 forms heteromeric complexes with Otx2 in the tectal anlage and binding to 

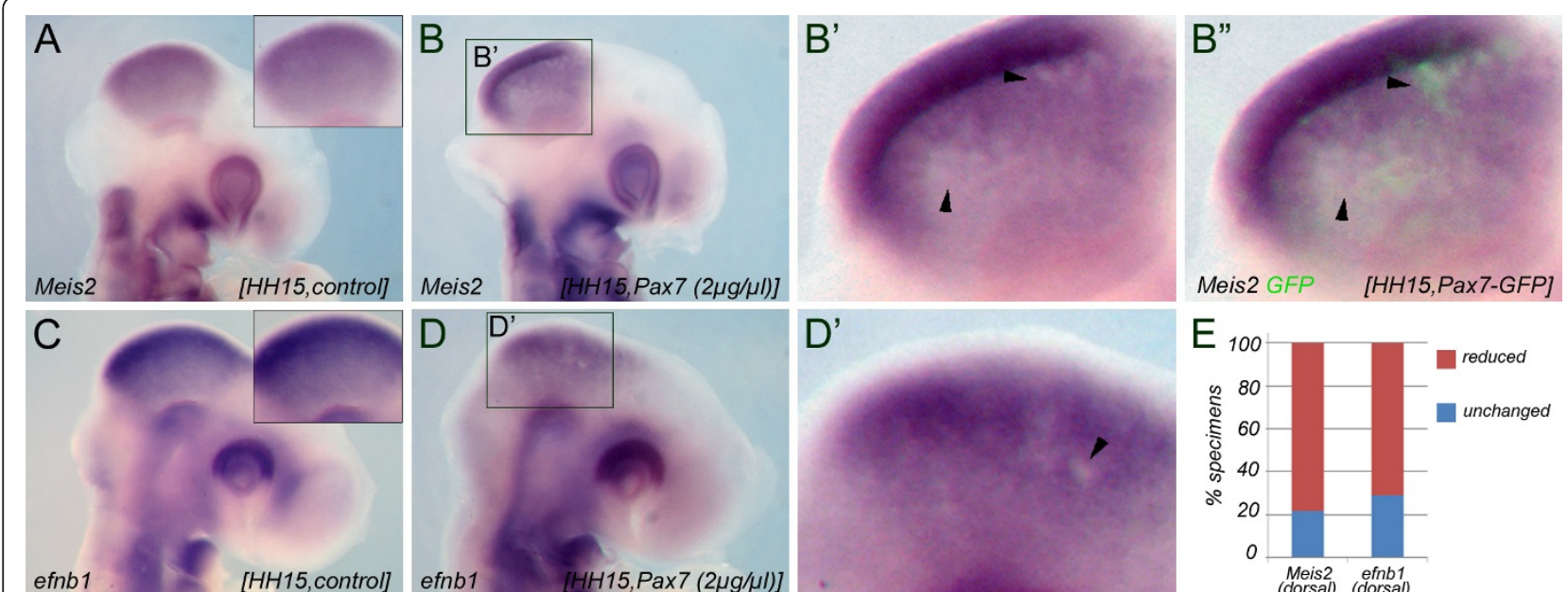
[HH15, control]
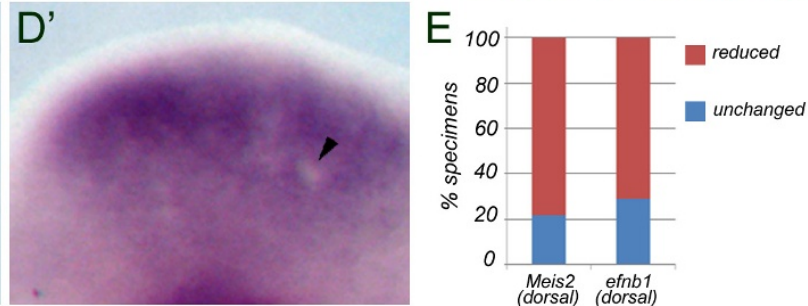

Figure 3 Pax7 represses Meis2 and efnb1 in the mesencephalic vesicle. (A-B $\left.{ }^{\prime \prime}\right)$ Meis2 expression in HH15 chick embryos electroporated with $2 \mu \mathrm{g} / \mu \mathrm{l}$ of a control vector carrying only GFP $(\mathbf{A})$ or $2 \mu \mathrm{g} / \mu \mathrm{l}$ pMES-Pax7 (B, $\left.\mathbf{B}^{\prime \prime}\right)$ into the right wall of the mesencephalic vesicle. The insert in $(\mathbf{A})$ shows a higher magnification and continuous expression of Meis2 in the control embryo. (B') is a higher magnification of the boxed area in (B). Arrowheads point to patches of cells with reduced Meis2 transcripts. In ( $\left.\mathbf{B}^{\prime \prime}\right)$ the GFP fluorescence of the specimen shown in (B and $\left.\mathbf{B}^{\prime}\right)$ is superimposed to visualize the extent of Pax7/GFP transfection. (C-D') efnb1 expression in a HH15 chick embryo transfected with a control vector (C) or with pMES-Pax7 (D, $\left.\mathbf{D}^{\prime}\right)$ under identical experimental conditions. ( $\mathbf{D}^{\prime}$ ) is a higher magnification of (D). (E) Quantification of the results: percent specimens with reduced (red bars) and unaltered (blue bars) Meis2 or efnb1 expression following targeted electroporation of pMES-Pax7.

Meis2 is necessary for Otx2 to induce ectopic tectal development upon misexpression in the metencephalic alar plate [17]. Based on these observations and because of the two proteins only Meis 2 expression is specific for the prospective optic tectum (Otx2 is present in the entire neural tube anterior of the MHB), we had suggested that complex formation with Meis 2 may confer tectal specificity to Otx2 in the dorsal midbrain, where both transcription factors are co-expressed. Pax3 and Pax 7 can also trigger ectopic tectal development when misexpressed [11]. However, like for Otx2, their expression is not specific for the tectal anlage, but includes the alar plate along most of its length [11]. We therefore decided to examine whether Meis2 may interact with Pax3 or Pax7 in the dorsal mesencephalic vesicle. In GST-pull down experiments using a GST-tagged form of Meis2 and protein extracts prepared from $\mathrm{HH}$ 15-18 chick mesencephalic vesicle Pax3 and Pax7 readily precipitated with Meis2-GST but not with GST alone. Pax3 and Pax7 can thus associate with recombinant Meis2 (Figure 5A, left half, top and bottom panels). When Meis2-specific antibodies were used to precipitate endogenous Meis2-containing protein complexes Pax3 and Pax7 were successfully enriched in the precipitates. Isotype-specific control antibodies, however, were not successful (Figure 5A, right half, top and bottom panels). Precipitation of Pax7 was significantly reduced when a truncated form of Meis2 lacking the MEINOX domain fused to GST (Meis2 ${ }_{[199-400]}, \Delta \mathrm{MD}$ ) was used and completely abolished when a truncated form lacking the homeodomain fused to GST (Meis $2_{[1-190]}, \Delta \mathrm{HD}$; Figure $5 \mathrm{~B}, \mathrm{C})$ was used.

To confirm that both truncated forms are active, we tested them for their ability to bind to the PBC class homeodomain protein $\mathrm{Pbx} 1$, a known Meis interacting partner, or to DNA respectively. Meis proteins bind to PBC class proteins via their MEINOX domain, a bipartite protein interaction domain located $\mathrm{N}$-terminal of the homeodomain (Figure 5B) [27]. Accordingly, full length Meis2 and Meis $2 \Delta H D$ successfully precipitated Pbx1b, whereas Meis $2 \Delta M D$ and GST were ineffective (Figure 5D). Meis family proteins recognize variations of the consensus sequence motif 5'-TGATA(A/G)-3' in the regulatory regions of target genes [28]. Although Meis proteins frequently cooperate with $\mathrm{PBC}$ class proteins in binding to DNA, examples of Pbx independent DNA binding are also known [29]. We therefore performed electromobility shift assays (EMSA) with purified Meis2GST fusion proteins and a ${ }^{32} \mathrm{P}$-labeled oligonucleotide probe, which was previously shown to be bound by Meis independently of Pbx [29]. Complex formation of the probe was observed with full-length Meis2 and Meis $2 \Delta \mathrm{MD}$ but not with Meis2 $\Delta \mathrm{HD}$ or GST alone (Figure $5 \mathrm{E}$ ). Excess of a non-labeled specific oligonucleotide effectively competed for full length Meis2 or Meis2 $\triangle M D$ DNA binding (Figure 5E and data not shown).

GST-fusion proteins lacking the amino acids $\mathrm{N}$-terminal to the MEINOX domain (Meis $2_{[64-400]} \Delta \mathrm{N}$ ) or Meis2 lacking the transactivation domain, which is located C-terminal to the homeodomain (Meis $2_{[1-338]} \Delta \mathrm{C}$ ), also effectively 


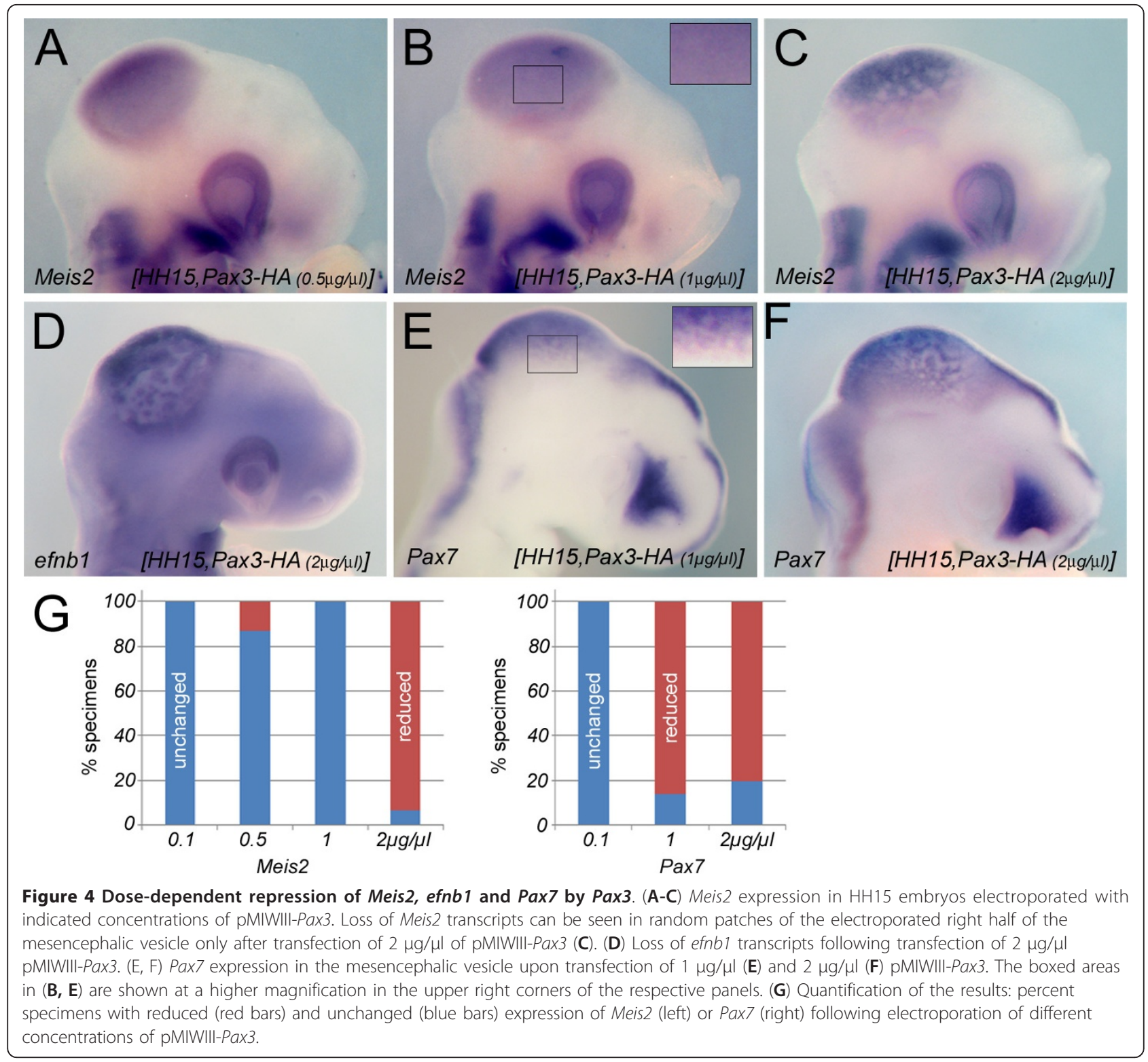

precipitated Pax3 and Pbx1b (Figure 5F) [17,30]. We therefore conclude that the MEINOX domain and homeodomain of Meis2 are involved in the association with Pax3 and Pax7. Complex formation between Meis2 and Pax7 was also seen when an antibody specific for Pax7 was used in the immunoprecipitation experiments (Figure 5G). The relatively weak Meis2-specific band in the IP with the Pax7-specific antibody compared to the robust co-precipitation of Pax7 with the Meis2-specific antibody may indicate that only a fraction of the Meis 2 protein present in the extracts is bound to Pax7 (compare immunoprecipitate with $\alpha$-Meis2 in Figure 5A (upper right panel) and immunoprecipitate with $\Delta$-Pax7 in Figure 5G). To test whether Meis2 forms multimeric complexes with Pax7 and Otx2, we re-probed the blot with an antibody directed against Otx2 (Figure 5H). Contrary to Meis2, Otx2 was not detected in the immunoprecipitate. We were also not able to precipitate Pax7 with an Otx2 specific antibody (data not shown). Although we cannot rule out that the antibodies used in our precipitation experiments may, to different extents, interfere with the ability of their antigens to engage in multiprotein interactions, our results argue against the existence of large multimeric complexes involving Meis2, Otx2 and Pax7. Instead, we propose that Meis2 may form heteromeric complexes with either Pax3 or Pax7 or Otx2 in the dorsal mesencephalic vesicle.

\section{Discussion}

Based on in ovo electroporation and immunoprecipitation experiments in chick embryos, we here provide 


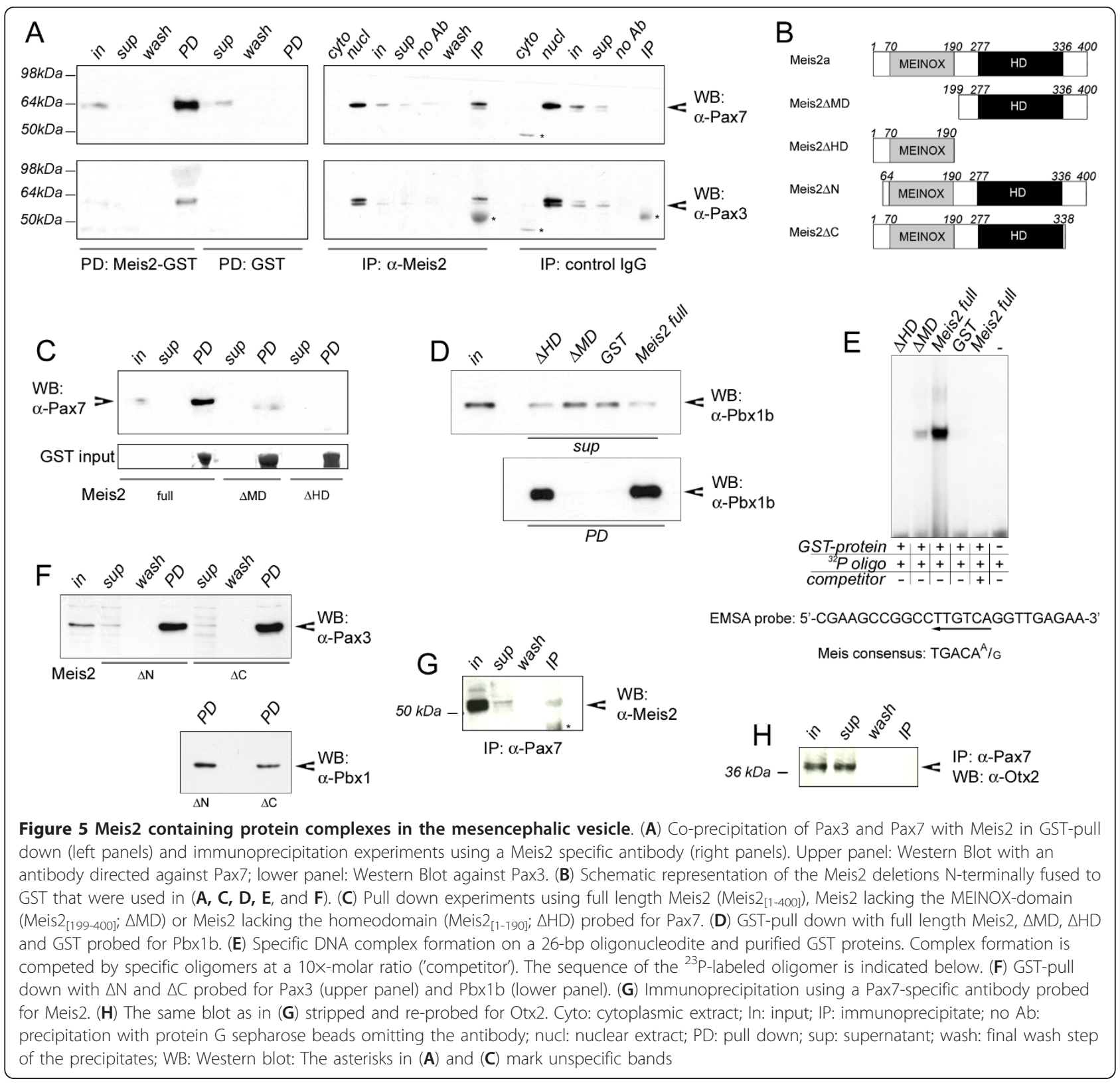

experimental evidence for reciprocal regulation and subsequent physical interaction of Pax3, Pax7 and Meis2 in the tectal anlage.

\section{Dose-dependent and reciprocal regulation of Pax3 and Pax7 in the tectal anlage}

Interdependent regulation between $\operatorname{Pax} 3$ and $\operatorname{Pax} 7$ has been reported in other physiological contexts before. Pax7 transcripts, for instance, are upregulated in the embryonic dorsal spinal cord of Splotch mice, a naturally occurring mutant of $\mathrm{Pax} 3$, suggesting that in mouse spinal cord $P a x 3$ normally functions to repress Pax7 [14]. In Xenopus laevis embryos, on the other hand, expression of $\operatorname{Pax} 7$ and $\operatorname{Pax} 3$ in the neural tube and neural crest strikingly differs from that in mice and chicks, which indicates different functional specifications of both genes in amphibians compared to mammals and birds [12]. Indeed, Morpholino-mediated knock down of Pax3 or misexpression of a function blocking form of Pax3 reduced Pax 7 transcript levels in the Xenopus spinal cord, suggesting that $\operatorname{Pax} 3$ positively regulates Pax7 in amphibians [12]. Although species specific differences obviously exist, in summation these results argue for interdependent regulation of $\operatorname{Pax} 3$ and $\operatorname{Pax} 7$ in the spinal cord. The observations reported in the present study extend this reciprocal regulation of both Pax 
proteins to the embryonic mesencephalon and point to a possible dose-dependent function of $\operatorname{Pax} 3$ during tectal development. Since $P a x 3$ and $P a x 7$ are closely related and forced expression of either molecule in the diencephalon leads to identical cell fate changes, Pax3 and $\operatorname{Pax} 7$ were suggested to play redundant functions during tectal development $[11,31]$. The cross-regulation between $P a x 3$ and Pax7 we report here may allow for a tight, mutual regulation of both gene products, which prevents over-activation of shared downstream pathways and at the same time permits functional compensation if one of the genes is mutated.

Examples for dose dependent functions of transcriptional regulators are well known in invertebrate development. In the early D. melanogaster embryo, for instance, spatial gradients of transcription factors control the expression of distinct sets of target genes, which ultimately control morphogenesis [32-34]. Similar dose dependent activities have also been reported for transcription factors that engage in reciprocal regulation. Oligodendrocyte differentiation in the embryonic vertebrate spinal cord, for instance, depends on the concerted activities of Olig2, Sox11 and Nkx2.2. This process not only requires mutual regulation of the three proteins but also depends on the gene dosage of Olig2, as both haploinsufficiency and overexpression of Olig2 significantly delayed oligodendrocyte maturation [35]. Dosage dependent developmental defects also exist for the paired-type transcription factor Pax 6 in both human and mice [36,37]. Mice heterozygote for PAX6 (Sey, small eye) display ocular defects with small eyes and malformations of the anterior eye chamber, as do mice carrying multiple copies of a PAX6-containing YAC (yeast artificial chromosome) [38-40]. The underlying mechanism of such dosage dependent requirement of transcriptional regulators is only partially understood at present. One evident explanation takes into account that transcription factors frequently function in the context of larger multiprotein complexes, which involve other DNA binding proteins as well as transcriptional co-regulators that modulate chromatin dynamics. Since the stoichiometry of these transcriptional complexes must be tightly controlled, too much or too little of any given component may disturb the formation of functional complexes and consequently result in insufficient transcriptional activity. Changing the intracellular concentration of individual transcription factors into either direction may therefore adversely affect expression of their target genes and ultimately lead to similar developmental defects.

An intriguing second explanation of how the net activation of an enhancer can be directly linked to different concentrations of a given transcription factor comes from studies of transcription factor gradients in early $D$. melanogaster embryos. Here, the bicoid protein binds individual recognition sites in the regulatory region of its target gene hunchback with different affinities. This ensures that high-affinity binding sites can already be bound and activated by low concentrations of the protein, whereas high bicoid levels are needed to activate low-affinity sites [41]. Likewise, Rowan and colleagues recently reported that the PAX6 lens enhancer was synergistically regulated by multiple Prep 1 proteins, each non-cooperatively bound to a low-affinity binding site [42]. Both examples provide a mechanism of how different concentrations of a given transcription factor can be directly translated into the net activity of a target enhancer. Pax3 may therefore directly modulate $\mathrm{Pax} 7$ and Meis 2 expression, potentially by binding to target sides in the enhancers of each gene that differ in their relative affinity for $\operatorname{Pax} 3$ (Figure 6A, dashed lines). A detailed comparison of the midbrain-specific regulatory regions of Meis 2 and Pax 7 would be needed to test this hypothesis. However, although upstream regulatory elements of $\operatorname{Pax} 7$ have been identified, none of them faithfully recapitulates expression in the mesencephalic alar plate and Meis 2 enhancer elements have remained elusive so far [43]. Nevertheless it is worth pointing out that recognition sequences with different binding affinities for Pax3 have been identified in vitro and that differences in the affinity of $\operatorname{Pax} 3$ to these sites mediate varying levels of transactivation [44].

Alternatively, $P a x 3$ and $P a x 7$ may control Meis 2 expression indirectly (Figure 6A, solid lines). This model takes into account that both Pax proteins were shown to trigger expression of $\mathrm{MHB}$ associated genes,

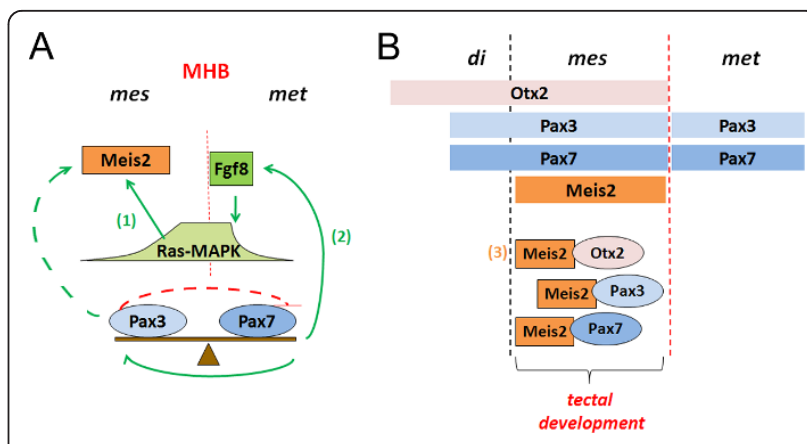

Figure 6 Model for a possible cooperation of Meis2, Pax3, Pax7 and Otx2during tectal development. See text for details. Red lines indicate negative regulation, green arrows positive regulation. Dashed lines indicate hypothetical direct regulation of the Meis2 promoter/enhancer by different Pax3 concentrations. Solid lines indicate indirect regulation of Meis2 expression via Pax3/7 mediated induction of Fgf8 as previously reported: (1) Regulation of Meis2 expression in response to Ras-MAPK signaling levels reported in [19]; (2) Induction of Fgf8 by Pax3 and Pax7 reported in [11]; (3) Existence of Meis2-Otx2 containing protein complexes in the tectal anlage reported in [17]. 
including $F g f 8$, when ectopically expressed in the anterior neural tube [11]. We have previously found that Meis 2 transcriptional activation requires low levels of Ras-MAPK pathway activity that are characteristic for the mesencephalic vesicle, but is inhibited by strong Ras-MAPK signals, which induce metencephalic fate specification [19]. Hence, $\operatorname{Pax} 3$ and $\operatorname{Pax} 7$ might impinge on Meis 2 expression indirectly through modulating Fgf8 expression levels (and consequently the resulting strength of Ras-MAPK pathway activation) at the MHB organizer. Irrespective of whether $\operatorname{Pax} 3$ and $\operatorname{Pax} 7$ act directly or indirectly on Meis 2 expression, interdependent and balanced expression of both paired proteins may serve to prevent excessive autoactivation of Meis 2 in the tectal anlage.

\section{Multiple transcriptional regulators associate with Meis2 in the tectal anlage}

Functional subdivision of the brain is preceded by the restricted expression of transcriptional regulators at neural tube stages. The anlagen of the optic tecta, originating from the alar plates of the mesencephalic vesicle, for instance are characterized by the combinatorial expression of Otx2, Pax3, Pax7, and Meis2 (Figure 6B). Notably, all four proteins can instruct tectal fate when ectopically delivered to the alar plate of adjacent brain vesicles, but only Meis 2 expression faithfully demarcates the prospective optic tecta. Otx2 expression encompasses the entire neural tube anterior of the MHB and Pax3 and Pax7 are present in the alar plates along most of the neural tubes anterior-posterior axis $[11,17,45]$.

As we demonstrated previously, Meis 2 forms heteromeric complexes with Otx2 in the mesencephalon and association with Meis 2 can restore full transcriptional activity of Otx 2 in the presence of the co-repressor Tle4 in an Otx2 dependent reporter assay [17]. This observation prompted us to suggest that Meis 2 may act as tectum-specific cofactor of Otx2. We can now extend this observation to include Pax3 and Pax7. Association of Meis 2 with Pax3 and Pax7 was observed in vitro and endogenous Meis2-Pax containing protein complexes could be precipitated from tectal tissue. Notably however, we failed to detect interaction of Pax7 and Otx2, suggesting that Meis2 forms individual complexes with each of these proteins.

The identification of Meis2-Pax containing nuclear complexes has also implications for the general concept of TALE-HD protein function. All Pax proteins except Pax4 and Pax6 contain an octapeptide motif, a conserved stretch of eight amino acids related to the eh1 domain. The eh1 domain mediates transcriptional repressor activity through recruitment of co-repressors of the Tle/Grg family. Indeed, Pax3 can directly associate with Grg4 or other transcriptional co-repressors and has been implicated in transcriptional repression in several physiological contexts [46-48]. The Meis2 - Pax3/7 interaction reported here suggests that Meis2 can be part of transcriptional activator as well as repressor complexes. In this context it is worth noting that tectal fate specification not only requires the activation of tectum specific genes, but also the repression of competing cellular fates. Indeed, Meis 2 is not only positively regulates the expression of tectum associated genes such as efnb1 or $D b x 1$, but also represses the diencephalic marker gene Pax6 [17].

\section{Conclusion}

We have previously shown that the TALE-homeodomain protein Meis2 acts downstream of the MHB organizer and controls tectal development by cooperating with Otx2. The results described here expand this view and suggest that tectal Meis 2 expression levels are modulated by Pax3 and Pax7 and that the expression levels of both Pax proteins have to be tightly balanced to allow for expression of Meis2. In addition, we find that Meis 2 not only associates with Otx2 in dorsal mesencephalic vesicle but also with Pax 3 and Pax7. Meis 2 is the only known transcriptional regulator so far that is able to instruct tectal fate specification and whose expression specifically marks the tectal anlage at mid to late somite stages. We therefore propose that spatially controlled association with Meis2 may serve as a general mechanism to confer tectal specificity to a wide range of otherwise broadly expressed transcription factors.

\section{Methods}

\section{Expression constructs, in ovo electroporation}

Full length coding regions of $\operatorname{Pax} 3$ and $P a x 7$ were cloned by RT-PCR from total RNA of HH16-20 chick optic tecta (primer sequences available upon request) and corresponded to NCBI Acc\# NM_204269 (Pax3) and NCBI Acc\# NM_205065 (Pax7) respectively. To generate pMIWIII-Pax3-HA, the coding region of chick Pax3 was fused to a triple HA tag and cloned into the chick expression vector pMIWIII [49]. Full length Pax7 was subcloned into pMES, which contains an IRESeGFP (internal ribosome entry site - enhanced green fluorescent protein) cassette to allow Pax7 expression together with GFP, resulting in pMES-Pax7 [50]. Unless otherwise noted, $2 \mu \mathrm{g} / \mu \mathrm{l}$ of each construct were electroporated into the right wall of the neural tube of $\mathrm{HH} 9$ 11 chick embryos as described (White Leghorn) [22,51]. In the case of pMIWIII $0.5 \mu \mathrm{g} / \mu \mathrm{l}$ pMIWIII-GFP, expressing enhanced green fluorescent protein, was co-electroporated for visualization. pMIWIII-GFP or pMES served as controls. All experiments involving fertilized chick eggs were performed in accordance with the guidelines of the local animal care committee. 


\section{In-situ hybridization}

In-situ hybridization on vibratome sections or whole embryos was performed as described in $[22,51]$. The cDNAs used to generate in-situ probes for Meis2, efnb1, Pax3, Pax7, and Nkx6.1 were gifts from D. O'Leary (Salk Institute, La Jolla, CA, USA), H. Rohrer (Max Planck Institute for Brain Research, Frankfurt, Germany), P. Gruss (Max Planck Institute for Biophysical Chemistry, Göttingen, Germany), J. Rubenstein (UCSF, San Francisco, CA, USA) or were cloned from chick HH10-12 whole head total RNA by RT-PCR with gene specific primers (primer sequences are available upon request).

\section{Isolation and analysis of Meis2 interacting proteins Preparation of tectal lysates}

Approximately $30 \mathrm{HH} 15-18$ chick tecta per experiment were lysed in $10 \mathrm{mM}$ Hepes pH8, $10 \mathrm{mM} \mathrm{KCl,} 0.1 \mathrm{mM}$ EDTA, 2 mM DTT, 1\% Igepal (Sigma Aldrich, Germany), and Complete ${ }^{\mathrm{TM}}$ protease inhibitor tablets (Roche, Germany). Cell nuclei were collected by brief centrifugation. The supernatant contained the cytosolic fraction ('cyto'). The cell nuclei were reconstituted in 10 $\mathrm{mM}$ Hepes pH8, $10 \mathrm{mM} \mathrm{KCl}, 0.1 \mathrm{mM}$ EDTA, $2 \mathrm{mM}$ DTT, $400 \mathrm{mM} \mathrm{NaCl}, 1 \%$ Igepal and Complete ${ }^{\mathrm{TM}}$ protease inhibitors and incubated for $15 \mathrm{~min}$ at $4^{\circ} \mathrm{C}$ under constant rotation. Cellular debris was removed by brief centrifugation ('nucl'). Cytosolic and nuclear fractions were combined (designated input, 'in'). Lysates were pre-cleared by incubation with empty glutathione sepharose 4B beads (GE Healthcare-Amerham, NJ) or empty Protein-G agarose beads (Roche, Germany) for $30 \mathrm{~min}$ to 1 hour under constant rotation at $4^{\circ} \mathrm{C}$.

\section{GST-pull down experiments}

Full length Meis $2 a$ (Meis $\left.2 a_{[1-400]}\right)$, the truncated variants Meis $2 a_{\text {[1-190] }}$ (lacking the C-terminus including the homeodomain, $\Delta \mathrm{HD})$, Meis $2 a_{\text {[199-400] }}$ (lacking the N-terminus including the MEINOX-domain, $\triangle \mathrm{MD}$ ), Meis $2 a$ [64-400] (lacking the N-terminus but retaining the MEINOX domain, $\Delta \mathrm{N}$ ) or Meis $2 a_{[1-338]}$ (lacking the C-terminal transcriptional activation domain but retaining the homeodomain, $\Delta \mathrm{C}$ ) were $\mathrm{N}$-terminally fused to glutathione S-transferase (GST). GST-fusion proteins were purified following standard procedures. Immobilized GST-fusion proteins were incubated with pre-cleared tectal lysates for 2 hours under constant rotation at $4^{\circ} \mathrm{C}$. Following extensive washes in $10 \mathrm{mM}$ Hepes $\mathrm{pH} 8,10$ $\mathrm{mM} \mathrm{KCl}, 0.1 \mathrm{mM}$ EDTA, $2 \mathrm{mM}$ DTT, $150 \mathrm{mM} \mathrm{NaCl}$, $1 \%$ Igepal and Complete ${ }^{\mathrm{TM}}$, the protein complexes were analyzed by SDS-PAGE followed by Western Blot following standard procedures.

\section{Co-immunoprecipitation assay}

Pre-cleared tectal lysates were incubated with polyclonal anti-Meis 2 antibody (generously provided by Dr. Arthur
Buchberg, Thomas Jefferson University Medical School, Philadelphia) or monoclonal anti-Pax7 antibody (Developmental Study Hybridoma Bank, Iowa City, IA) overnight at $4^{\circ} \mathrm{C}$ under constant rotation. Protein-G agarose beads (Roche, Germany) were added for 1 hour at $4^{\circ} \mathrm{C}$ rotating. After extensive washes, the immunoprecipitates were separated by SDS-PAGE and analyzed by Western Blot. For Western Blot monoclonal anti-Pax3 (mouse, DHSB, IA; 1:5); monoclonal anti-Pax7 (mouse, DHSB, IA; 1:5); polyclonal Otx2 (goat, R\&D Systems, MN; 1:2000), or polyclonal anti-Meis2 (rabbit, A. Buchberg, 1:30.000) were used.

\section{Electromobility shift assays}

Radioactively labeled oligonucleotide probes (5'CGAAGCCGGCCTTGTCAGGTTGAGAA-3') were generated by annealing complementary single-strand oligonucleotides in a solution containing $10 \mathrm{mM}$ Tris pH7.5 and $20 \mathrm{mM} \mathrm{NaCl}$ and labeled with polynucleotide kinase (Roche, Germany) in the presence of $\gamma^{32} \mathrm{P}$-ATP. Binding reactions typically contained $2 \mu \mathrm{g}$ purified GST protein in a buffer containing $10 \mathrm{mM}$ Tris $\mathrm{HCl}(\mathrm{pH}$ 8.0), $150 \mathrm{mM} \mathrm{KCl,} 0.25 \mathrm{mM}$ EDTA, 12,5\% glycerol, 0.2 mM DTT, Complete ${ }^{\mathrm{TM}}$ protease inhibitor cocktail, $1 \mu \mathrm{g} /$ $\mu \mathrm{l}$ bovine serum albumin and $1 \mu \mathrm{g}$ poly $(\mathrm{dIdC})$ and were incubated for 10 minutes at room temperature. 20.000 cpm of the labeled probe were added and the reaction was incubated for further 30 minutes. For competition experiments, a 10-fold molar excess of the non-labeled oligomer was mixed with the radiolabeled probe prior to addition of the proteins. DNA and DNA-protein complexes were resolved on $6 \%$ non-denaturing polyacrylamide gels.

\section{Acknowledgements}

We thank Christa Ziegler for excellent technical assistance and A. Buchberg, D. O' Leary, H. Rohrer, J. Rubenstein, and P. Gruss for reagents. The work was supported by a Junior Research Group grant of the Volkswagenstiftung (AW) and the Deutsche Forschungsgemeinschaft (DS). ZA was a recipient of a pre-doctoral fellowship from the Studienstiftung des Deutschen Volkes, NL was supported by a fellowship from the SFB 465 (DFG) and the Volkswagenstiftung, $\mathrm{AH}$ received a pre-doctoral fellowship from the International Max Planck Research School Program in Structure and Function of Biological Membranes.

\section{Author details}

${ }^{1}$ Institute of Neurology (Edinger Institute), J. W. Goethe University Medical School, Heinrich Hoffmannstr. 7, 50628 Frankfurt, Germany. ${ }^{2}$ Max Planck Institute for Brain Research, Deutschordenstr. 46, 50628 Frankfurt, Germany. ${ }^{3}$ JRG Developmental Neurobiology, Biocenter, Julius Maximilians University, Am Hubland, 97074 Würzburg, Germany. "Department of Pharmacology, Howard Hughes Medical Institute, and the Institute for Stem Cell and Regenerative Medicine, University of Washington School of Medicine, Seattle, WA98109, USA. ${ }^{5}$ Department of Neurosurgery, Tianjin Medical University General Hospital, Tianjin 300052, China. ${ }^{6}$ Helmholtz Center Munich, German Research Center for Environmental Health, Neuherberg, Germany. ${ }^{\text {Institute }}$ of Anatomy, Experimental Embryology, Eberhard Karls University, Tübingen, Germany. 


\section{Authors' contributions}

ZA carried out the in ovo electroporation and in situ hybridization experiments (except Figure 2) as well as the biochemical analyses. NL performed the experiments shown in Figure 2. AH contributed to the electroporation experiments. DS and AW designed and coordinated the study, DS wrote the manuscript. All authors read and approved the final manuscript.

Received: 22 September 2011 Accepted: 5 March 2012 Published: 5 March 2012

\section{References}

1. Acampora D, Mazan S, Lallemand Y, Avantaggiato V, Maury M, Simeone A, Brulet P: Forebrain and midbrain regions are deleted in Otx2-/- mutants due to a defective anterior neuroectoderm specification during gastrulation. Development 1995, 121:3279-3290.

2. Matsuo I, Kuratani S, Kimura C, Takeda N, Aizawa S: Mouse Otx2 functions in the formation and patterning of rostral head. Genes Dev 1995, 9:2646-2658.

3. Ang SL, Jin O, Rhinn M, Daigle N, Stevenson L, Rossant J: A targeted mouse Otx2 mutation leads to severe defects in gastrulation and formation of axial mesoderm and to deletion of rostral brain. Development 1996, 122:243-252.

4. Wurst $W$, Bally-Cuif $L$ : Neural plate patterning: upstream and downstream of the isthmic organizer. Nat Rev Neurosci 2001, 2:99-108.

5. Bally-Cuif $\mathrm{L}$, Wassef M: Ectopic induction and reorganization of Wnt-1 expression in quail/chick chimeras. Development 1994, 120:3379-3394.

6. Martinez S, Wassef M, Alvarado-Mallart RM: Induction of a mesencephalic phenotype in the 2-day-old chick prosencephalon is preceded by the early expression of the homeobox gene en. Neuron 1991, 6:971-981.

7. Nakamura H, Nakano KE, Igawa HH, Takagi S, Fujisawa H: Plasticity and rigidity of differentiation of brain vesicles studied in quail-chick chimeras. Cell Differ 1986, 19:187-193.

8. Itasaki N, Nakamura H: Rostrocaudal polarity of the tectum in birds: correlation of en gradient and topographic order in retinotectal projection. Neuron 1992, 8:787-798.

9. Crossley PH, Martinez S, Martin GR: Midbrain development induced by FGF8 in the chick embryo. Nature 1996, 380:66-68.

10. Martinez S, Crossley PH, Cobos I, Rubenstein JL, Martin GR: FGF8 induces formation of an ectopic isthmic organizer and isthmocerebellar development via a repressive effect on Otx2 expression. Development 1999, 126:1189-1200.

11. Matsunaga $\mathrm{E}$, Araki I, Nakamura H: Role of Pax3/7 in the tectum regionalization. Development 2001, 128:4069-4077.

12. Maczkowiak F, Matéos S, Wang E, Roche D, Harland R, Monsoro-Burq AH: The Pax3 and Pax7 paralogs cooperate in neural and neural crest patterning using distinct molecular mechanisms, in Xenopus laevis embryos. Dev Biol 2010, 340:381-339.

13. Holland LZ, Schubert M, Kozmik Z, Holland ND: AmphiPax3/7, an amphioxus paired box gene: insights into chordate myogenesis, neurogenesis, and the possible evolutionary precursor of definitive vertebrate neural crest. Evol Dev 1999, 1:153-165.

14. Borycki AG, Li J, Jin F, Emerson CP, Epstein JA: Pax3 functions in cell survival and in Pax7 regulation. Development 1999, 126:1665-1674.

15. Mansouri A, Stoykova A, Torres M, Gruss P: Dysgenesis of cephalic neural crest derivatives in Pax7-/- mutant mice. Development 1996, 121:831-838.

16. Relaix F, Rocancourt $D$, Mansouri A, Buckingham M: Divergent functions of murine Pax3 and Pax7 in limb muscle development. Genes Dev 2004, 18:1088-1105.

17. Agoston Z, Schulte D: Meis2 competes with the Groucho co-repressor Tle4 for binding to Otx2 and specifies tectal fate without induction of a secondary midbrain-hindbrain boundary organizer. Development 2009, 136:3311-3322.

18. Moens CB, Selleri L: Hox cofactors in vertebrate development. Dev Biol 2006, 291:193-206.

19. Vennemann A, Agoston Z, Schulte D: Differential and dose-dependent regulation of gene expression at the mid-hindbrain boundary by RasMAP kinase signaling. Brain Res 2008, 1206:33-43.

20. Rubenstein JL, Shimamura K, Martinez S, Puelles L: Regionalization of the prosencephalic neural plate. Annu Rev Neurosci 1998, 21:445-477.
21. Nomura T, Kawakami A, Fujisawa H: Correlation between tectum formation and expression of two PAX family genes, PAX7 and PAX6, in avian brains. Dev Growth Differ 1998, 40:485-495.

22. Li N, Hornbruch A, Klafke R, Katzenberger B, Wizenmann A: Specification of dorsoventral polarity in the embryonic chick mesencephalon and its presumptive role in midbrain morphogenesis. Dev Dyn 2005, 233:907-920.

23. Thompson JA, Zembrzycki A, Mansouri A, Ziman M: Pax7 is requisite for maintenance of a subpopulation of superior collicular neurons and shows a diverging expression pattern to Pax3 during superior collicular development. BMC Dev Biol 2008, 8:62.

24. Hamburger V, Hamilton HL: A Series of Normal Stages in the Development of the Chick Embryo. J Morphol 1951, 88:1-49.

25. Marti E, Bumcrot DA, Takada R, McMahon AP: Requirement of $19 \mathrm{~K}$ form of Sonic hedgehog for induction of distinct ventral cell types in CNS explants. Nature 1995, 375:322-325.

26. Roelink H, Porter JA, Chiang C, Tanabe Y, Chang DT, Beachy PA, Jessell TM: Floor plate and motor neuron induction by different concentrations of the amino-terminal cleavage product of sonic hedgehog autoproteolysis. Cell 1995, 81:445-455.

27. Choe SK, Vlachakis N, Sagerström CG: Meis family proteins are required for hindbrain development in the zebrafish. Development 2002, 129:585-595.

28. Chang CP, Jacobs Y, Nakamura T, Jenkins NA, Copeland NG, Cleary ML: Meis proteins are major in vivo DNA binding partners for wild-type but not chimeric Pbx proteins. Mol Cell Biol 1997, 17:5679-5687.

29. Zhang X, Friedman A, Heaney S, Purcell P, Maas RL: Meis homeoproteins directly regulate Pax6 during vertebrate lens morphogenesis. Genes Dev 2002, 16:2097-2107.

30. Hyman-Walsh C, Bjerke GA, Wotton D: An autoinhibitory effect of the homothorax domain of Meis2. FEBS J 2010, 277:2584-2597.

31. Noll M: Evolution and role of Pax genes. Curr Opin Genet Dev 1993, 3:595-605.

32. Driever W, Nüsslein-Volhard C: The bicoid protein determines position in the Drosophila embryo in a concentration-dependent manner. Cell 1988, 54:95-104.

33. Struhl G, Struhl K, Macdonald PM: The gradient morphogen bicoid is a concentration-dependent transcriptional activator. Cell 1989, 57:1259-1273.

34. Roth S, Stein D, Nüsslein-Volhard C: A gradient of nuclear localization of the dorsal protein determines dorsoventral pattern in the Drosophila embryo. Cell 1989, 59:1189-1202.

35. Liu Z, Hu X, Cai J, Liu B, Peng X, Wegner M, Qiu M: Induction of oligodendrocyte differentiation by Olig2 and Sox10: evidence for reciprocal interactions and dosage-dependent mechanisms. Dev Biol 2007, 302:683-693.

36. Hill RE, Favor J, Hogan BL, Ton CC, Saunders GF, Hanson IM, Prosser J, Jordan T: Hastie ND, van Heyningen V: Mouse small eye results from mutations in a paired-like homeobox-containing gene. Nature 1991, 354:522-525.

37. Glaser T, Jepeal L, Edwards JG, Young SR, Favor J, Maas RL: PAX6 gene dosage effect in a family with congenital cataracts, aniridia, anophthalmia and central nervous system defects. Nat Genet 1994, 7:463-471.

38. Schedl A, Ross A, Lee M, Engelkamp D, Rashbass $P$, van Heyningen $V$, Hastie ND: Influence of PAX6 gene dosage on development: overexpression causes severe eye abnormalities. Cell 1996, 86:71-82

39. van Raamsdonk CD, Tilghman SM: Dosage requirement and allelic expression of PAX6 during lens placode formation. Development 2000, 127:5439-5448.

40. Davis-Silberman N, Kalich T, Oron-Karni V, Marquardt T, Kroeber M, Tamm ER, Ashery-Padan R: Genetic dissection of Pax6 dosage requirements in the developing mouse eye. Hum Mol Genet 2005, 14:2265-2276.

41. Driever W, Siegel V, Nüsslein-Volhard C: Autonomous determination of anterior structures in the early Drosophila embryo by the bicoid morphogen. Development 1990, 109:811-820.

42. Rowan S, Siggers T, Lachke SA, Yue Y, Bulyk ML, Maas RL: Precise temporal control of the eye regulatory gene Pax6 via enhancer-binding site affinity. Genes Dev 2010, 24:980-985.

43. Lang D, Brown CB, Milewski R, Jiang YQ, Lu MM, Epstein JA: Distinct enhancers regulate neural expression of Pax7. Genomics 2003, 82:553-560, 
44. Phelan SA, Loeken MR: Identification of a new binding motif for the paired domain of Pax-3 and unusual characteristics of spacing of bipartite recognition elements on binding and transcription activation. $J$ Biol Chem 1998, 273:19153-19159.

45. Katahira T, Sato T, Sugiyama S, Okafuji T, Araki I, Funahashi J, Nakamura H: Interaction between Otx2 and Gbx2 defines the organizing center for the optic tectum. Mech Dev 2000, 91:43-52.

46. Lang D, Lu MM, Huang L, Engleka KA, Zhang M, Chu EY, Lipner S, Skoultchi A, Millar SE, Epstein JA: Pax3 functions at a nodal point in melanocyte stem cell differentiation. Nature 2005, 433:884-887.

47. Magnaghi P, Roberts C, Lorain S, Lipinski M, Scambler PJ: HIRA, a mammalian homologue of Saccharomyces cerevisiae transcriptional corepressors, interacts with Pax3. Nat Genet 1998, 20:74-77.

48. Chalepakis G, Jones FS, Edelman GM, Gruss P: Pax-3 contains domains for transcription activation and transcription inhibition. Proc Natl Acad Sci USA 1994, 91:12745-12749.

49. Suemori H, Kadodawa Y, Goto K, Araki I, Kondoh H, Nakatsuji N: A mouse embryonic stem cell line showing pluripotency of differentiation in early embryos and ubiquitous beta-galactosidase expression. Cell Differ Dev 1990, 29:181-186.

50. Swartz ME, Eberhart J, Pasquale EB, Krull CE: EphA4/ephrin-A5 interactions in muscle precursor cell migration in the avian forelimb. Development 2001, 128:4669-4680.

51. Heine P, Dohle E: Bumsted-O'Brien K, Engelkamp D, Schulte D: Evidence for an evolutionary conserved role of homothorax/Meis $1 / 2$ during vertebrate retina development. Development 2008, 135:805-811.

doi:10.1186/1471-213X-12-10

Cite this article as: Agoston et al:: Genetic and physical interaction of Meis2, Pax3 and Pax7 during dorsal midbrain development. BMC

Developmental Biology 2012 12:10.

\section{Submit your next manuscript to BioMed Central and take full advantage of:}

- Convenient online submission

- Thorough peer review

- No space constraints or color figure charges

- Immediate publication on acceptance

- Inclusion in PubMed, CAS, Scopus and Google Scholar

- Research which is freely available for redistribution

Submit your manuscript at www.biomedcentral.com/submit 